Article

\title{
Activity and Transcriptional Responses of Hepatopancreatic Biotransformation and Antioxidant Enzymes in the Oriental River Prawn Macrobrachium nipponense Exposed to Microcystin-LR
}

\author{
Julin Yuan ${ }^{1,2}$, Xueqin Wang ${ }^{1}$, Zhiming Gu ${ }^{2}$, Yingying Zhang ${ }^{1}$ and Zaizhao Wang ${ }^{1, *}$ \\ 1 College of Animal Science and Technology, Northwest A \& F University, \\ Shaanxi Key Laboratory of Molecular Biology for Agriculture, Yangling 712100, Shaanxi, China; \\ E-Mails: yuanjulin1982@hotmail.com (J.Y.); wangxueqin1988@hotmail.com (X.W.); \\ yingyingz2008@hotmail.com (Y.Z.) \\ 2 Zhejiang Institute of Freshwater Fisheries, Freshwater Fishery Healthy Breeding Laboratory of \\ Ministry of Agriculture, Huzhou 313001, Zhejiang, China; E-Mail: guzhimin2006@hotmail.com \\ * Author to whom correspondence should be addressed; E-Mail: zzwang@nwsuaf.edu.cn; \\ Tel.: +86-29-8709-2139; Fax: +86-29-8709-2164.
}

Academic Editor: Luis M. Botana

Received: 19 July 2015 / Accepted: 18 September 2015 / Published: 8 October 2015

\begin{abstract}
Microcystins (MCs) are a major group of cyanotoxins with side effects in many organisms; thus, compounds in this group are recognized as potent stressors and health hazards in aquatic ecosystems. In order to assess the toxicity of MCs and detoxification mechanism of freshwater shrimp Macrobrachium nipponense, the full-length cDNAs of the glutathione $S$-transferase ( $g s t$ ) and catalase (cat) genes were isolated from the hepatopancreas. The transcription level and activity changes in the biotransformation enzyme (glutathione $S$-transferase (GST)) and antioxidant enzymes (superoxide dismutase (SOD), catalase (CAT), glutathione peroxidase (GPx)) in the hepatopancreas of $M$. nipponense exposed to MC-LR $(0.2,1,5$, and $25 \mu \mathrm{g} / \mathrm{L})$ for $12,24,72$ and $96 \mathrm{~h}$ were analyzed. The results showed that the isolated full-length cDNAs of cat and gst genes from M. nipponense displayed a high similarity to other crustaceans, and their mRNAs were mainly expressed in the hepatopancreas. MC-LR caused significant increase of GST activity following 48-96 h $(p<0.05)$ and an increase in SOD activity especially in $24-$ and 48 -h exposures. CAT activity was activated when exposed to MC-LR in 12-, 24- and 48-h exposures and then it was inhibited at 96-h exposure. There was no significant effect on GPx activity after the 12- and
\end{abstract}


24-h exposures, whereas it was significantly stimulated after the 72- and 96-h exposures $(p<0.05)$. The transcription was altered similarly to enzyme activity, but the transcriptional response was generally more immediate and had greater amplitude than enzymatic response, particularly for GST. All of the results suggested that MC-LR can induce antioxidative modulation variations in M. nipponense hepatopancreas in order to eliminate oxidative damage.

Keywords: microcystin-LR; biotransformation; antioxidant enzyme; gene expression

\section{Introduction}

Microcystins (MCs) are a family of cyclic peptide toxins produced by brackish and freshwater cyanobacteria of the genera Anabaena, Anabaenopsis, Chroococcus, Microcystis, Nostoc, and Planktothrix [1]. More than 80 structural variants have been identified, differing primarily in two $L$-amino acids. The major isoforms are microcystin-LR (MC-LR), microcystin-RR, and microcystin-YR [2]. Toxins are released into the surrounding medium during senescence and lysis of bloom cells, which affect many organisms, from terrestrial mammals to algae. In terrestrial mammals, MCs are selective for liver cells, irreversibly inhibiting serine/threonine protein phosphatases 1 (PP-1) and 2A (PP-2A), and causing disintegration of hepatocyte structure, apoptosis, necrosis, and internal hemorrhage in the liver which may lead to death by hemorrhagic shock [3-5]. Compared to terrestrial mammals, aquatic organisms are more frequently exposed to MCs. Studies with different fish species show that MCs can affect growth rate in Rutilus rutilus [6], histopathology in Cyprinus carpio [7], heart rate in Salmo trutta [8], blood index in Hypophthalmichthys molitrix and Aristichthys nobilis [9] and behaviour in Odontesthes bonariensis [10]. In aquatic invertebrate species, the effects of MCs mainly refer to the alteration of survival rate and feeding behavior of mussels [11] and bivalves [12], and the irreversible inhibition of serine/threonine protein phosphatases PP-1 and -2A is described in zooplankton [13]. In addition, several reports put forward that oxidative stress is also a toxicological consequence of the exposure to MCs in different aquatic organisms [14-16]. MCs could trigger excess reactive oxygen species (ROS), which result in lipid peroxidation (LPO), protein oxidation and DNA damage [16-18]. It is well known that aquatic organisms have developed a physiological antioxidant system, which involves antioxidant enzymes, such as superoxide dismutase (SOD), catalase (CAT), and glutathione peroxidase (GPx) and some non-enzymatic antioxidant molecule such as glutathione (GSH) [15,19]. These systems work together to eliminate the endogenous ROS (e.g., hydroxy radical, superoxide anion). Otherwise, GSTs, the most important enzymes for detoxifying MCs, are involved in the formation of a microcystin-glutathione conjugate, which enhances water solubility and has been detected in several aquatic organisms, including the crustacean Daphnia magna [20]. However, because of short-lived ROS in organs, the defense mechanism of aquatic invertebrate species induced by MCs still remains obscure and further studies are needed. The freshwater shrimp Macrobrachium nipponense is an important economic species bred widely in the Lake Tai region of China. The use of water contaminated with cyanobacteria in $M$. nipponense farms induced the obvious lower field production, which had caused enormous economic loss in recent years. In the present study, biotransformation and antioxidant enzymatic activity (GST, SOD, CAT and GPx) and transcriptional responses were monitored during 
12-, 24-, 72- and 96-h exposure to assess the toxicity of MC-LR and the aquatic invertebrate species' defense mechanism.

\section{Materials and Methods}

\subsection{Animals and Chemicals}

One-year-old adult $M$. nipponense (weight, $4.4 \pm 0.2 \mathrm{~g}$ ) were bought from Huzhou fish farm (Zhejiang, China) and raised in $50 \mathrm{~L}$ glass aquaria with aerated water, a controlled temperature of $25 \pm 2{ }^{\circ} \mathrm{C}$, and the photoperiod was a $14 \mathrm{~h}: 10 \mathrm{~h}$ light/dark cycle. Males were chosen to minimize possible interfering effects of sex. MC-LR (purity $\geq 98 \%$ ) was purchased from Alexis Biochemicals (Lauseanne, Switzerland).

\subsection{MC-LR Exposure}

M. nipponense were exposed to MC-LR or a solvent control $(0.05 \%$ methanol, $v / v)$ in a $20 \mathrm{~L}$ glass tank for 12, 24, 48, 72 and $96 \mathrm{~h}$ (15 individuals per tank in triplicate and approximately $3.3 \mathrm{~g}$ shrimp/L). The MC-LR doses were $0.2,1,5$, and $25 \mu \mathrm{g} / \mathrm{L}$, according to environmental content of MCs. Half of the exposure solution was changed every day in order to guarantee the concentration of MC-LR and water quality. They were fed with commercial pellet food once a day. Water quality was regularly monitored and no differences were recorded between tanks during the entire experimental period. No crayfish died during the exposure period. M. nipponense in each group were immediately sacrificed following exposure, and tissues were dissected, frozen in liquid nitrogen, and maintained at $-80{ }^{\circ} \mathrm{C}$ until use.

\subsection{Sampling, RNA Isolation, and Reverse Transcription (RT)}

M. nipponense hepatopancreas, muscle, stomach, intestine, and gill tissues were assayed for cat and gst mRNAs. Tissue samples for cDNA cloning and quantitative real-time polymerase chain reaction (qRT-PCR) analysis were homogenized in TRIZOL reagent (Invitrogen, Carlsbad, CA, USA), total RNA was extracted as described by Wang et al. [21], and treated with RNase-free DNase I (Fermentas, Burlington, ON, Canada) to remove genomic DNA contamination. Total RNA concentrations were calculated at an absorbance of $260 \mathrm{~nm}$. Total RNA quality was verified on 1\% agarose gels by visual inspection of the $18 \mathrm{~S}$ and $28 \mathrm{~S}$ ribosomal RNA bands and by the A260 nm/A280 nm ratio (range 1.90-2.05) measured with a Nanodrop spectrophotometer (Thermo Electron Corp., Waltham, MA, USA). The cDNAs were synthesized from $5 \mu \mathrm{g}$ total RNA with M-MLV reverse transcriptase (Invitrogen) and the oligo (dT) 18 primer in a $20 \mu \mathrm{L}$ final volume.

\subsection{Cloning of Full-Length Cat and Gst cDNAs from M. nipponense}

Partial cDNA fragments for the two target genes in $M$. nipponense were amplified using primers designed from the conserved regions of their counterparts in other crustaceans (Table S1). PCR was performed with $2 \mu \mathrm{L}$ of the cDNA template synthesized by RT-PCR in $20 \mu \mathrm{L}$ containing 5 pmol of each specific primer and 1 unit of Taq DNA polymerase (TaKaRa Bio, Shiga, Japan). The purified PCR products of these cDNA fragments were inserted into the $\mathrm{pMD} \mathrm{D}_{18} \mathrm{~T}$ plasmid using a TA cloning kit 
(TaKaRa Bio) following the manufacturer's instructions. Three confirmed recombinant plasmid clones for each gene were sequenced separately by Genscript Corp. (Nanjing, China), using the ABI 3730 automated DNA sequencer (BigDye Terminator Chemistry) and the BigDye Terminator Cycle Sequencing Kit (PE Biosystems, Foster City, CA, USA). The nucleotide sequences were determined for both sense and antisense strands of the plasmid inserts. The $3^{\prime}$ and $5^{\prime}$ ends of both cDNAs were obtained with several pairs of gene-specific primers designed for the target genes to overlap the sense or antisense regions of their amplified partial fragments sequenced above. The 5' and $3^{\prime}$ rapid amplification of cDNA ends (RACE) procedures were performed with the RACE cDNA Amplification Kit (Invitrogen), using total RNA and following the manufacturer's instructions, respectively. The nested 5'- and 3'-RACE PCR products of the expected size were processed and sequenced as described above. The cat and gst full-length cDNAs were assembled by aligning the partial cDNA fragments and the 5'- and 3'-RACE fragments using SeqMan in Lasergene software (DNASTAR, Madison, WI, USA).

\subsection{Protein Alignment and Phylogenetic Analyses}

The putative amino acid sequences of the M. nipponense cat and gst genes were aligned with their counterparts from other species using the Megalign program in Lasergene software. We aligned diverse invertebrate cat and gst genes at the amino acid level using the ClustalX (1.83) sequence alignment program to establish phylogenetic trees for the two M. nipponense genes [22]. The neighbor-joining algorithm method [23] in the Mega 4.0 program was used to construct the phylogenetic trees [24]. Bootstrap analyses were conducted using 1000 replicates.

\section{6. $q R T-P C R$}

The qRT-PCR analysis was performed on a CFX96 real-time PCR detection system (Bio-Rad, Hercules, CA, USA) thermocycler with the SYBR Premix ExTaq II kit (TaKaRa Bio). The qRT-PCR reactions were carried out in a final volume of $25 \mu \mathrm{L}$ using $1 \times$ SYBR Premix Ex Taq, $0.4 \mu \mathrm{M}$ of each primer, and $2.5 \mu \mathrm{L}$ RT reaction solution. The reactions were denatured at $95{ }^{\circ} \mathrm{C}$ for $30 \mathrm{~s}$, followed by 40 cycles of denaturation at $95{ }^{\circ} \mathrm{C}$ for $5 \mathrm{~s}$, and annealing at $60{ }^{\circ} \mathrm{C}$ for $30 \mathrm{~s}$. To assess the specificity of each amplicon, a melting curve analysis was performed at the end of each PCR thermal profile. CFX Manager software (Bio-Rad) was used to analyze SYBR Green I density and to determine the threshold cycle $(\mathrm{Ct})$ value. All samples were run in triplicate. qRT-PCR efficiency (E) was calculated from the given slopes using CFX Manager software and a 10-fold diluted cDNA sample series with five dilution points measured in triplicate. E was determined using the equation: $E=10 \frac{-1}{\text { slope }}[25]$.

\subsection{Tissue Distribution of the Cat and Gst Genes}

qRT-PCR was conducted with male $M$. nipponense hepatopancreas, intestine, gill, stomach, and muscle tissues to analyze tissue distribution of the cat and gst transcripts, with the $\beta$-actin gene as the endogenous control [26]. The qRT-PCR primers are listed in Table S1. The primers were tested during normal PCR amplification, and the PCR products were visualized on a $1.5 \%$ agarose gel before qRT-PCR to verify primer specificity. The relative changes in mRNA levels of the two genes in different 
tissues were calculated using the $2^{-\Delta \Delta C t}$ method [27]. The analysis was performed on tissues from nine males. All data are expressed as mean \pm standard deviation (SD).

\subsection{Enzyme Activity Assays Following MC-LR Exposure}

Nine hepatopancreatic samples from each group were defrosted twice and homogenized on ice with 10 volumes of cold buffer ( $250 \mathrm{mM}$ sucrose, $5 \mathrm{mM}$ Tris-HCL, and $0.1 \mathrm{mM}$ edetic acid-2Na; $\mathrm{pH} 7.5$ ). The homogenate was centrifuged at $13,000 \mathrm{~g}$ and $4{ }^{\circ} \mathrm{C}$ for $10 \mathrm{~min}$ to obtain the supernatant for the assays. Protein concentration was determined using a commercial protein assay kit (Nanjing Jiancheng Bioengineering Institute). GST, SOD, CAT, and GPx activities were measured using commercial kits (Nanjing Jiancheng Bioengineering Institute, Nanjing, China). One unit (U) of GST, CAT, and GPx activity was defined as the amount of enzyme consuming $1 \mu \mathrm{mol}$ of substrate or generating $1 \mu \mathrm{mol}$ of product $/ \mathrm{min} / \mathrm{mg}$ soluble protein (U/mg prot). One U of SOD activity was defined as the amount of enzyme required to inhibit the oxidation reaction by $50 \%$ and was also expressed as $\mathrm{U} / \mathrm{mg}$ prot.

\section{9. mRNA Expression of the Enzymes Following MC-LR Exposure}

The gene expression patterns of hepatopancreatic gst, $\mathrm{Cu} / \mathrm{Zn}$-sod, cat, and gpx were detected by qRT-PCR in M. nipponense after exposure to $0.2-25 \mu \mathrm{g} / \mathrm{L}$ MC-LR for $96 \mathrm{~h}$. Each transcript was analyzed in 9 individuals. The $\beta$-actin gene was used as an endogenous control. Relative mRNA levels were calculated using the $2^{-\Delta \Delta \mathrm{Ct}}$ method and the formula $\mathrm{F}=2^{-\Delta \Delta \mathrm{Ct}}, \Delta \Delta \mathrm{Ct}=\left(\mathrm{C}_{\mathrm{t}}\right.$, target gene $-\mathrm{C}_{\mathrm{t}}, \beta$-actin $)$ MC-LR -

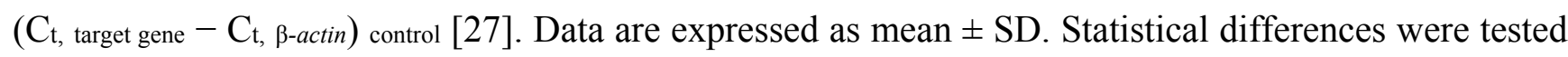
with analysis of variance and the least significant difference test.

\section{Results}

\subsection{Cloning and Molecular Characterization of the Cat and Gst Gene cDNAs}

The full-length cDNA sequences of cat (GenBank accession No. KC485002) and gst (GenBank accession No. KC485003) genes were determined by the RT-PCR and RACE methods. The cat cDNA was $1699 \mathrm{bp}$ and contained a $1554 \mathrm{bp}$ open reading frame (ORF) encoding a 518 amino acid polypeptide with a theoretical $\mathrm{pI}$ of 6.66 and a calculated molecular mass of $58.57 \mathrm{kDa}$ and $135 \mathrm{bp} \mathrm{5'-untranslated}$ region (UTR) (Figure S1). Meanwhile, the gst cDNA was 1122 bp and contained a 651 bp ORF encoding a 217 amino acid polypeptide with a theoretical pI of 5.35 and a calculated molecular weight of $25.45 \mathrm{kDa}, 173 \mathrm{bp}$ 5'-UTR and 298 bp 3'-UTRs with a polyadenylation signal (AATAAA) (Figure S2).

\subsection{Homology and Phylogenetic Analyses of the Putative Cat and Gst Amino Acid Sequences}

The putative CAT of $M$. nipponense contains NADPH binding site, proximal heme-ligand signature, and proximal active site signature (Figure S3). The amino acid sequence identities of $M$. nipponense CAT with its counterparts from other crustaceans were more than $80 \%$. The $M$. nipponense GST protein sequence showed $53.3 \%-72.1 \%$ similarity with the GST mu class from different organisms and had several conserved GSH binding sites and substrate binding sites (Figure S4). 
Two phylogenetic trees were constructed from the amino acid sequence alignments for CAT and GST in crustaceans, fish, and mammals using the neighbor-joining method to better understand the positions of $M$. nipponense CAT and GST in the evolutionary history of the respective proteins. $M$. nipponense CAT was more similar to its counterpart in Macrobrachium rosenbergii (Figure 1). GST was more similar to its counterpart in Lepeophtheirus salmonis than those of other crustaceans and fish (Figure 2).

\subsection{Tissue Distributions for Cat and Gst mRNAs}

The cat and gst tissue distributions in M. nipponense are shown in Figure 3. Both cat and gst mRNAs were expressed predominantly in the hepatopancreas. Meanwhile, cat and gst mRNAs were expressed at low level in other tissues with decreasing order of stomach, muscle, intestines and gill. The cat and gst mRNA levels in hepatopancreas were 80.1-fold and 16.8-fold higher than in intestine, respectively.

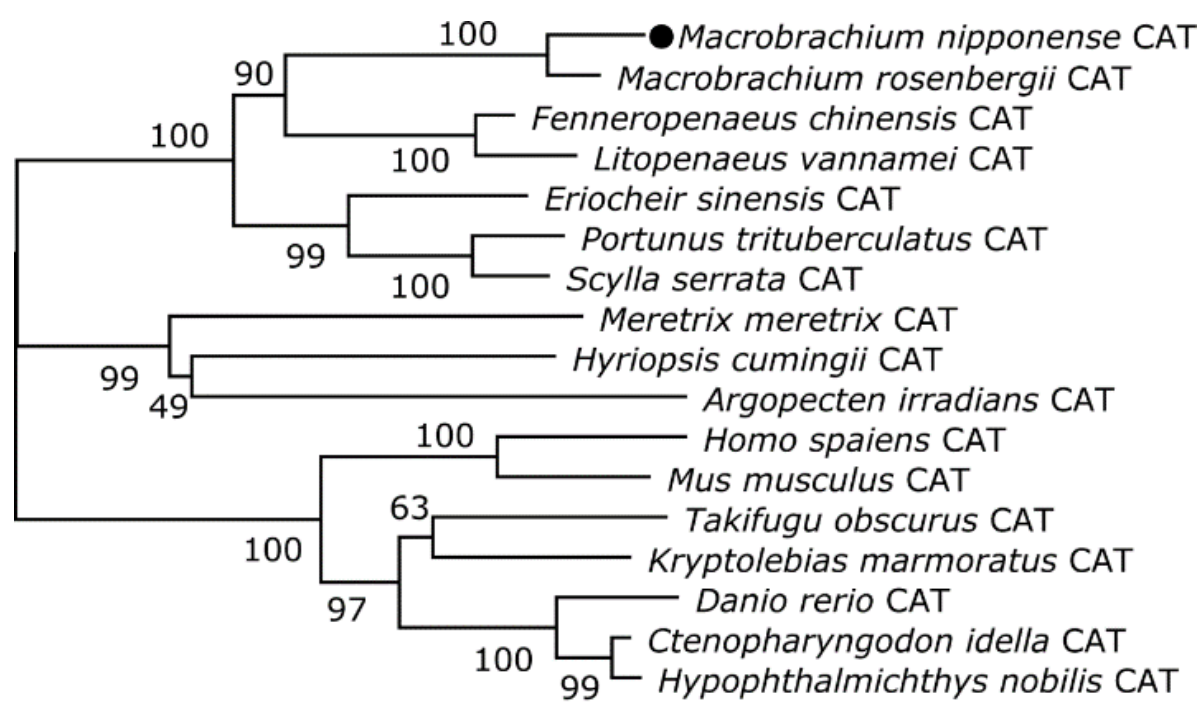

$\overline{0.02}$

Figure 1. The phylogenetic tree was constructed based on a deduced amino acid alignment for M. nipponense CAT and its counterparts in other species using the neighbor-joining method. The accession numbers for the sequences are as follows: Macrobrachium rosenbergii, HQ668089; Fenneropenaeus chinensis, EU102287; Litopenaeus vannamei, JX162772; Eriocheir sinensis, GU361618; Portunus trituberculatus, FJ152102; Scylla serrata, GQ892832; Meretrix meretrix, JQ005875; Hyriopsis cumingii, HM188565; Argopecten irradians, HQ025801; Homo sapiens, NM_001752; Mus musculus, NM_009804; Takifugu obscurus, EF667052; Kryptolebias marmoratus, EU116026; Danio rerio, NM130912; Ctenopharyngodon idella, FJ560431; and Hypophthalmichthys nobilis, HM564034. Bootstrap values (\%) are indicated (1000 replicates). Scale bar indicates 0.02 expected amino acid substitutions per site. 


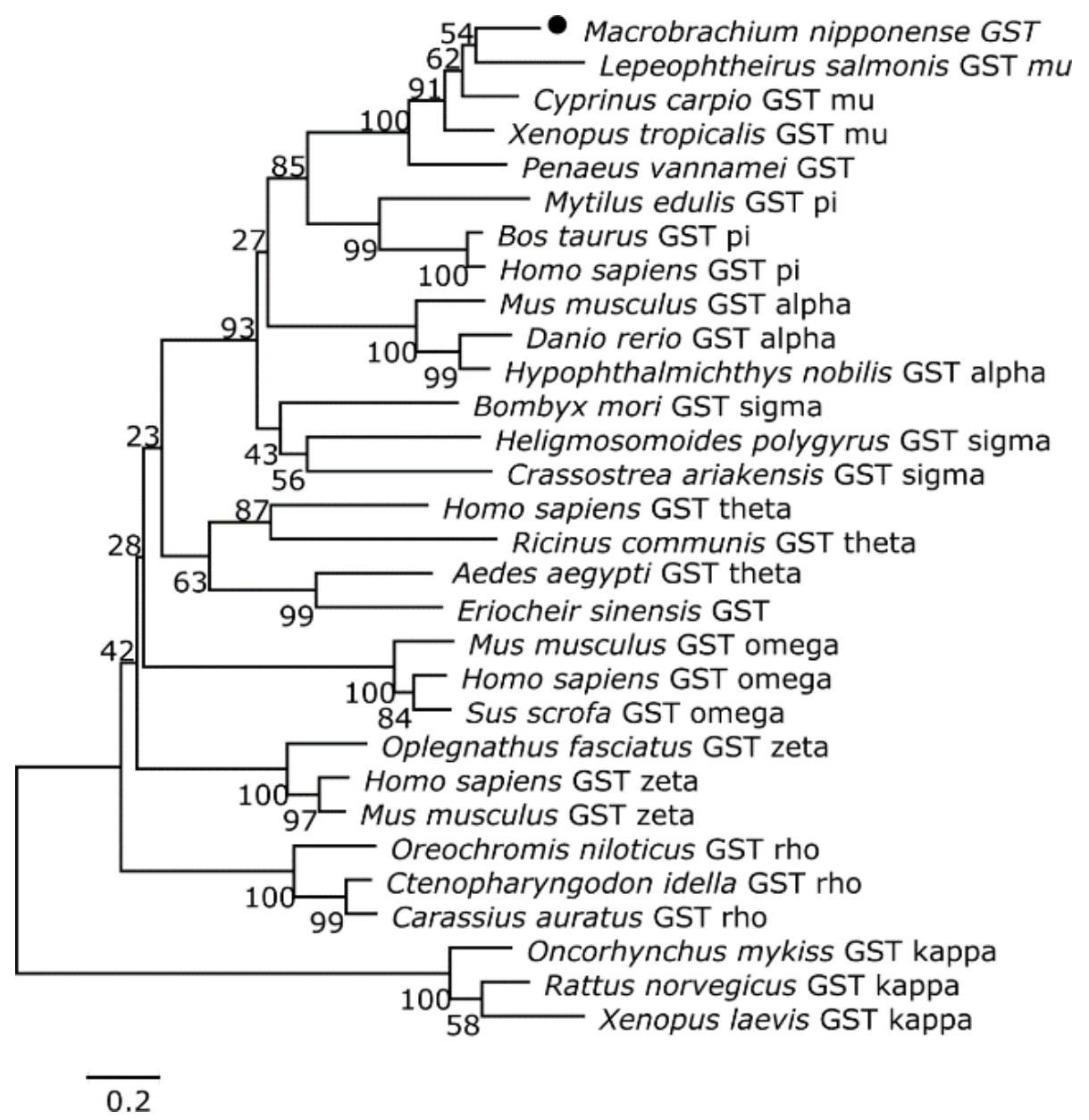

Figure 2. The phylogenetic tree was constructed based on a deduced amino acid alignment for M. nipponense GST and its counterparts in other species using the neighbor-joining method. The accession numbers for the sequences are as follows: Lepeophtheirus salmonis GST mu, BT121603; Cyprinus carpio GST mu, DQ411312; Xenopus tropicalis GST mu, NM001004964; Penaeus vannamei GST, AY573381; Mytilus edulis GST pi, AY557404; Bos taurus GST pi, NM_177516; Homo sapiens GST pi, BC010915; Mus musculus GST alpha, BC012639; Danio rerio GST alpha, NM_213394; Hypophthalmichthys nobilis GST alpha, EF100902; Bombyx mori GST sigma, NM_001043529; Heligmosomoides polygyrus GST sigma, AF128959; Crassostrea ariakensis GST sigma, EU908270; Homo sapiens GST theta, NM_000853; Ricinus communis GST theta, XM002535811; Aedes aegypti GST theta, AY819712; Eriocheir sinensis GST, GQ325712; Mus musculus GST omega, NM_010362; Homo sapiens GST omega, NM_004832; Sus scrofa GST omega, NM_004832; Oplegnathus fasciatus GST zeta, GU938679; Homo sapiens GST zeta, NM_145870; Mus musculus GST zeta, NM_010363; Oreochromis niloticus GST rho, EU107284; Ctenopharyngodon idella GST rho, EU107283; Carassius auratus GST rho, EU527005; Oncorhynchus mykiss GST rho, NM_001165133; Rattus norvegicus GST kappa, NM_181371; and Xenopus laevis GST kappa, NM_001086734. Bootstrap values (\%) are indicated (1000 replicates). Scale bar indicates 0.2 expected amino acid substitutions per site. 

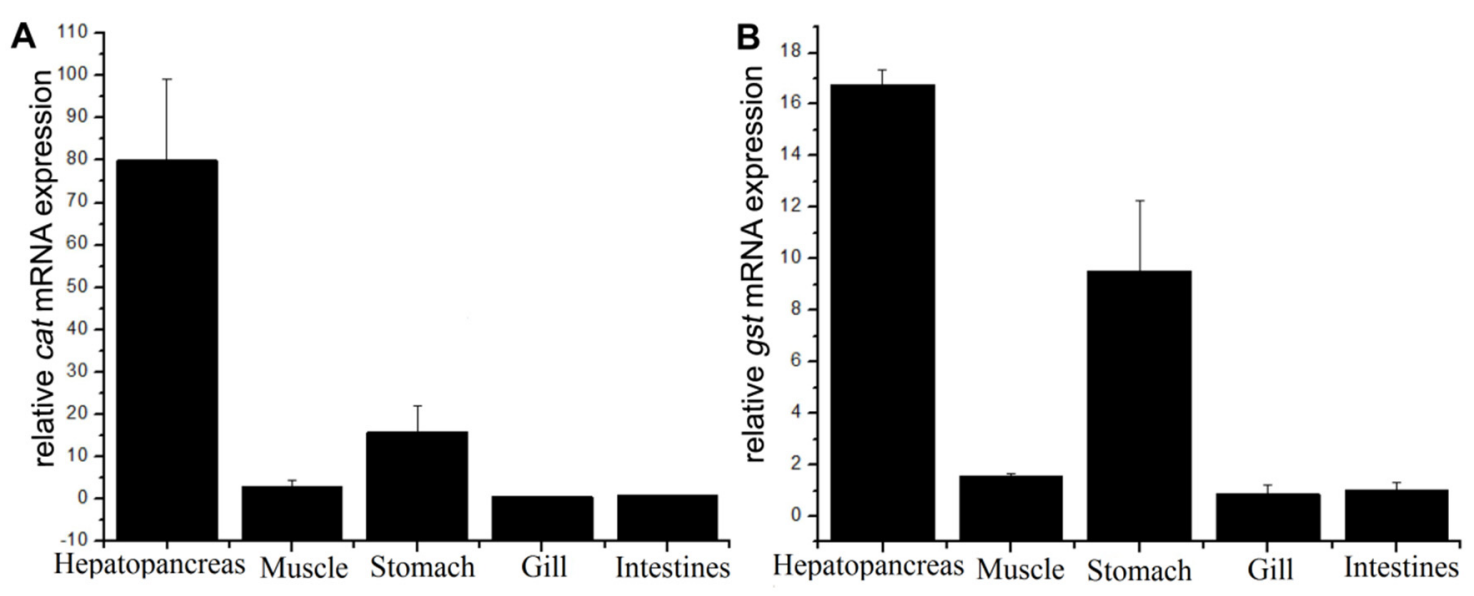

Figure 3. mRNA tissue distributions of cat (A) and gst (B) in M. nipponense tissues of hepatopancreas, muscle, stomach, gill and intestines analyzed by quantitative reverse transcription-polymerase chain reaction analysis. The values were calibrated with the $\beta$-actin endogenous control. Values are expressed as mean \pm standard deviation $(n=9)$.

\subsection{Effect of MC-LR on Biotransformation Enzyme and Antioxidant Enzymes}

MC-LR had no effect on GST activity after the 12- and 24-h exposures (Figure 4A), but GST activity increased significantly following MC-LR exposure at four concentrations for 48-96 h, except MC-LR exposure at $1 \mu \mathrm{g} / \mathrm{L}$ for $48 \mathrm{~h}$ and $0.2 \mu \mathrm{g} / \mathrm{L}$ for $96 \mathrm{~h}$ (Figure 4A).

MC-LR at 5 and $25 \mu \mathrm{g} / \mathrm{L}$ caused a significant increase in SOD activity after the $12-\mathrm{h}$ exposure, compared with control $(p<0.05$, Figure 4B). At the same time, 0.2-25 $\mu \mathrm{g} / \mathrm{L}$ MC-LR all significantly stimulated SOD activity in the $24-$ and 48 -h exposures (1.06-1.38 times, $p<0.05$, Figure $4 \mathrm{~B})$. Amounts of 0.2 and $5 \mu \mathrm{g} / \mathrm{L}$ MC-LR also significantly increased SOD activity in the 72-h exposure $(p<0.05$, Figure 4B), but 1 and $25 \mu \mathrm{g} / \mathrm{L}$ MC-LR did not increase SOD activity. However, in the 96-h exposure, $25 \mu \mathrm{g} / \mathrm{L}$ MC-LR significantly inhibited SOD activity, while MC-LR at $0.2-5 \mu \mathrm{g} / \mathrm{L}$ had no significant effect ( $p<0.05$, Figure 4B).

In 12-h exposure, only $25 \mu \mathrm{g} / \mathrm{L}$ MC-LR significantly stimulated CAT activity, while $0.2-5 \mu \mathrm{g} / \mathrm{L}$ MC-LR had no significant effect (Figure 4C). In 24-h exposure, MC-LR at $0.2-25 \mu \mathrm{g} / \mathrm{L}$ all significantly increased CAT activity (Figure 4C). In 48-h exposure, 0.2 and $1 \mu \mathrm{g} / \mathrm{L}$ MC-LR caused 1.8- and 1.4-fold significant increases in CAT activity, respectively ( $p<0.05$, Figure 4C), while 5 and $25 \mu \mathrm{g} / \mathrm{L} \mathrm{MC-LR}$ had no significant effect. For 72-h exposure, all MC-LR treatments did not affect CAT activity. MC-LR at 1 and $25 \mu \mathrm{g} / \mathrm{L}$ significantly suppressed CAT activity after the 96-h exposure, whereas 0.2 and $5 \mu \mathrm{g} / \mathrm{L}$ MC-LR had no significant effect (Figure 4C).

It was interesting that none of the MC-LR concentrations had a significant effect on GPx activity in the 12- and 24-h exposures (Figure 4D). MC-LR at 0.2 and $5 \mu \mathrm{g} / \mathrm{L}$ significantly enhanced GPx activity after the 48-h exposure, whereas 1 and $25 \mu \mathrm{g} / \mathrm{L}$ MC-LR did not change GPx activity. In the 72- and 96-h exposures, MC-LR at $0.2-25 \mu \mathrm{g} / \mathrm{L}$ all significantly stimulated GPx activity ( $p<0.05$, Figure 4D). 

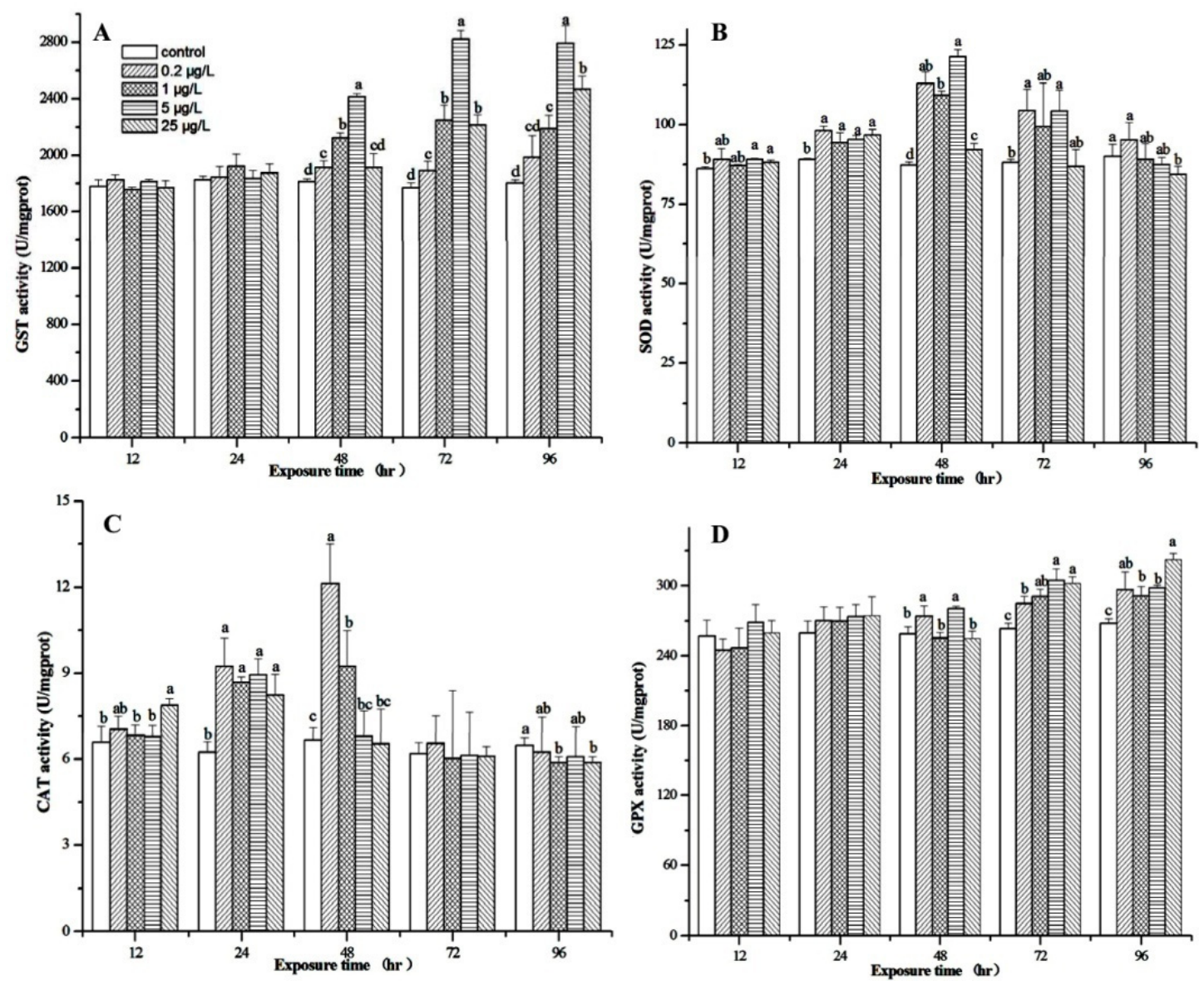

Figure 4. Glutathione $S$-transferase (GST) (A); superoxide dismutase (SOD) (B); catalase (CAT) (C); and glutathione peroxide (GPx) (D) enzyme activities in the hepatopancreas of male $M$. nipponense after MC-LR exposure for 12, 24, 48, 72 and $96 \mathrm{~h}$ at different concentrations. Values are expressed as mean \pm standard deviation. Different lowercase letters indicate significant differences $(p<0.05)$, and different capital letters indicate highly significant differences $(p<0.01)$.

3.5. Expression Profiles of M. nipponense Gst, Cu/Zn-sod, Cat, and Gpx in the Hepatopancreas After MC-LR Exposure

The changes in gst, $\mathrm{Cu} / \mathrm{Zn}$-sod, cat and gpx mRNA expression are shown in Figure 5. The gst mRNA expression was significantly up-regulated 1.41-fold by $25 \mu \mathrm{g} / \mathrm{L}$ MC-LR after the 12-h exposure $(p<0.05)$ (Figure 5A), whereas MC-LR at the lower concentrations $(0.2-5 \mu \mathrm{g} / \mathrm{L})$ had no significant effect. In 24-h exposure, MC-LR at 5 and $25 \mu \mathrm{g} / \mathrm{L}$ significantly elevated gst transcription 1.62 and 1.73-fold, respectively (Figure 5A), while 0.2 and $1 \mu \mathrm{g} / \mathrm{L}$ MC-LR did not significantly affect it. In 48-h exposure, MC-LR at 1-25 $\mu \mathrm{g} / \mathrm{L}$ caused 1.51-1.98-fold significant increases in gst transcription. In 72- and 96-h exposures, MC-LR at $0.2-25 \mu \mathrm{g} / \mathrm{L}$ all significantly up-regulated $g s t$ expression (1.25-2.06-fold, 1.39-2.07-fold, respectively, $p<0.05$, Figure 5A).

In 12-h exposure, MC-LR at 1-25 $\mu \mathrm{g} / \mathrm{L}$ caused 1.57-1.84-fold significant increase in $\mathrm{Cu} / \mathrm{Zn}-$ sod transcript $(p<0.05$ ), while $0.2 \mu \mathrm{g} / \mathrm{L}$ MC-LR had no significant effect (Figure 5B). After 24-h exposure, MC-LR at $0.2,5$, and $25 \mu \mathrm{g} / \mathrm{L}$ significantly elevated $\mathrm{Cu} / \mathrm{Zn}$-sod transcription (1.33-2.69-fold, $p<0.05)$, whereas $1 \mu \mathrm{g} / \mathrm{L}$ MC-LR had no significant effect. In 48-h exposure, $\mathrm{Cu} / \mathrm{Zn}$-sod expression was 
significantly up-regulated for 2.46 and 1.3 fold by 0.2 and $1 \mu \mathrm{g} / \mathrm{L}$ MC-LR, respectively, whereas MC-LR at higher concentrations ( 5 and $25 \mu \mathrm{g} / \mathrm{L}$ ) had no significant effect on $\mathrm{Cu} / \mathrm{Zn}-$ sod transcription. In $72-\mathrm{h}$ exposure, $\mathrm{Cu} / \mathrm{Zn}$-sod was significantly up-regulated and down-regulated by 0.2 and $25 \mu \mathrm{g} / \mathrm{L}$ MC-LR, respectively. However, 1 and $5 \mu \mathrm{g} / \mathrm{L}$ MC-LR had no effect. Both 1 and $25 \mu \mathrm{g} / \mathrm{L}$ MC-LR significantly down-regulated $\mathrm{Cu} / \mathrm{Zn}$-sod expression after the $96-\mathrm{h}$ exposure and MC-LR at 0.2 and $5 \mu \mathrm{g} / \mathrm{L}$ tended to inhibit $\mathrm{Cu} / \mathrm{Zn}$-sod transcription (Figure 5B).
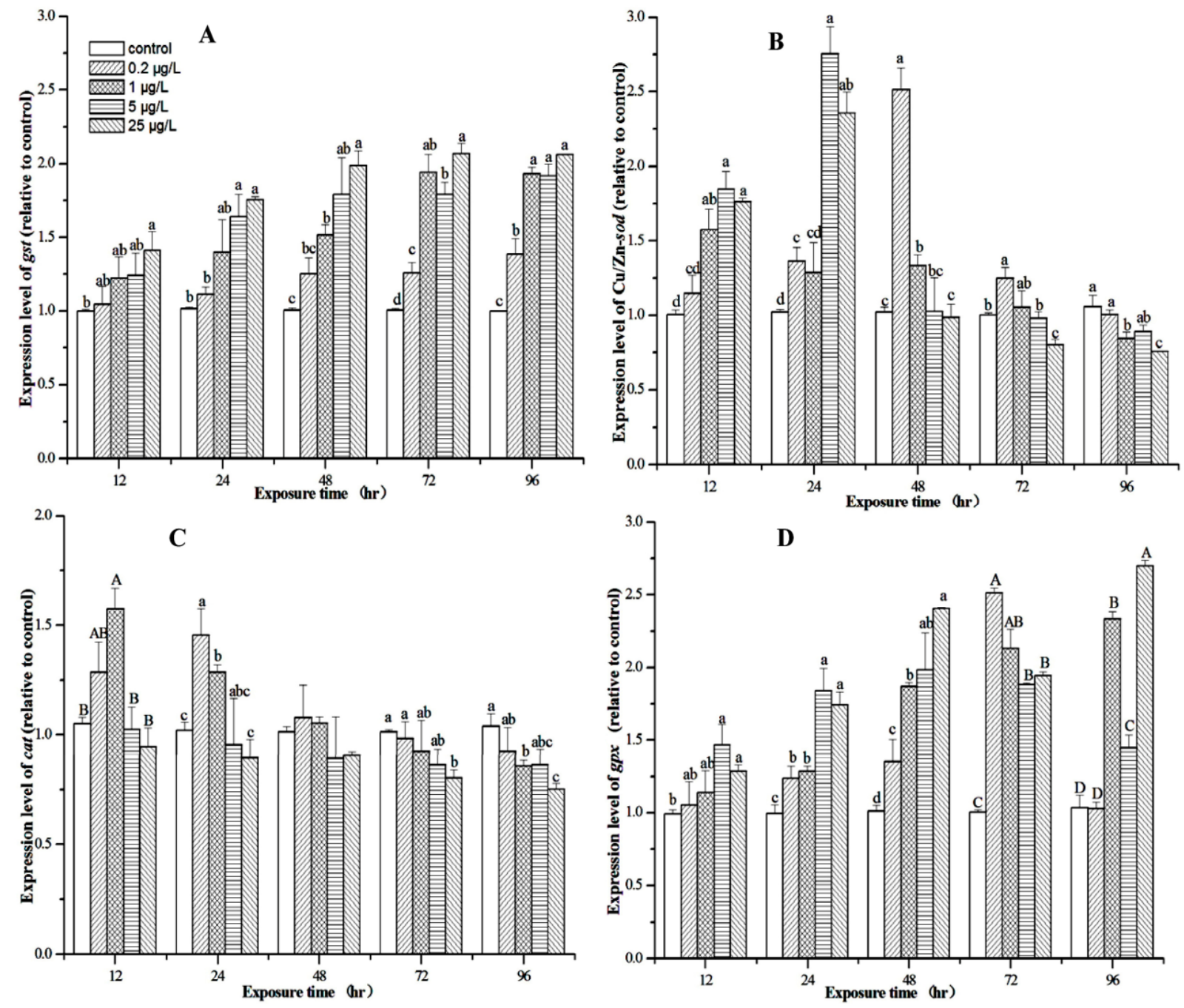

Figure 5. Relative glutathione $S$-transferase ( $g s t)(\mathbf{A}) ; \mathrm{Cu} / \mathrm{Zn}$-superoxide dismutase (sod) (B); catalase (cat) (C); and glutathione peroxidase ( $g p x)$ mRNA expression (D) in the hepatopancreas of $M$. nipponense measured by quantitative reverse transcription-polymerase chain reaction analysis after acute microcystin (MC)-LR exposure for 12, 24, 48, 72 and $96 \mathrm{~h}$. The values were calibrated with the endogenous control $\beta$-actin. Each transcript abundance value is expressed as mean \pm standard deviation ( $n=9$ for each value). Different lowercase letters indicate significant differences $(p<0.05)$, and different capital letters indicate highly significant differences $(p<0.01)$.

After 12-h exposure, cat expression was significantly up-regulated by the $1 \mu \mathrm{g} / \mathrm{L} \mathrm{MC}-\mathrm{LR}$ for 1.57 -fold $(p<0.01$, Figure 5C), while MC-LR at 0.2, 5 and $25 \mu \mathrm{g} / \mathrm{L}$ all had no significant effect. In 24-h exposure, MC-LR at 0.2 and $1 \mu \mathrm{g} / \mathrm{L}$ significantly stimulated cat mRNA expression (1.4 and 1.2-fold, $p<0.05$, 
respectively), whereas MC-LR at higher concentrations ( 5 and $25 \mu \mathrm{g} / \mathrm{L}$ ) tended to inhibit its expression. In 72-h treatment, cat expression was significantly down-regulated by $25 \mu \mathrm{g} / \mathrm{L} \mathrm{MC-LR}(0.8$-fold, $p<0.05)$, and there was inhibitory tendency for cat expression in MC-LR at lower concentrations $(0.2-5 \mu \mathrm{g} / \mathrm{L})$. After 96-h exposure, MC-LR at 1 and $25 \mu \mathrm{g} / \mathrm{L}$ resulted in $0.82-$ and 0.72 -fold decreases of cat transcription, respectively ( $p<0.05$, Figure 5C), while MC-LR at 1 and $5 \mu \mathrm{g} / \mathrm{L}$ tended to inhibit its expression. However, 48-h MC-LR at 4 concentrations did not affect cat expression.

After 12-h exposure, MC-LR at 5 and $25 \mu \mathrm{g} / \mathrm{L}$ significantly increased gpx mRNA expression for 1.48- and 1.29-fold, respectively ( $p<0.05$, Figure 5D), while MC-LR at lower concentrations had no effect. During 24-h exposure, MC-LR at $0.2-25 \mu \mathrm{g} / \mathrm{L}$ all significantly up-regulated gpx mRNA expression (1.24-1.85-fold, $p<0.05)$. After 48-h exposure, 1-25 $\mu \mathrm{g} / \mathrm{L}$ MC-LR significantly stimulated gpx expression 1.85-2.38-fold, and 0.2 $\mu \mathrm{g} / \mathrm{L}$ MC-LR tended to increase gpx expression. During 72-h exposure, MC-LR at $0.2-25 \mu \mathrm{g} / \mathrm{L}$ caused 1.87-2.5-fold, significant increases in gpx transcript $(p<0.01)$. MC-LR at $1-25 \mu \mathrm{g} / \mathrm{L}$ significantly increased gpx transcript $1.4-2.6$ fold after 96-h exposure $(p<0.01)$ (Figure 5D), while $0.2 \mu \mathrm{g} / \mathrm{L} \mathrm{MC-LR}$ did not affect its expression.

\section{Discussion}

In this study, CAT and GST cDNA sequences cloned from M. nipponense were presented, and sequence alignment analysis demonstrated this CAT shared high identity $(>80 \%)$ with catalase from other crustaceans. The predicted size of the crayfish CAT polypeptide was $58.57 \mathrm{kDa}$, very close to swimming crab Portunus trituberculatus (58.57 kDa) [28], Chinese shrimp Fenneropenaeus chinensis (58.8 kDa) [29] and white shrimp Litopenaeus vannamei (57.6 kDa) [30]. The M. nipponense catalase proximal heme-ligand signature sequence (RLFSYNDTH) and the proximal active site signature (FDRERIPERVVHAKGAGA) were highly conserved with other species [31,32], which suggested that this CAT should have the same function with other species due to the conserved sequences and motif. Two ligand binding sites were present in GST. The G-sites were highly specific for glutathione binding sites and contained 11 highly conserved amino acids: $\operatorname{Tyr}^{7}, \mathrm{Arg}^{13}, \operatorname{Trp}^{38}, \mathrm{Lys}^{46}, \mathrm{Gln}^{53}, \mathrm{Leu}^{54} \mathrm{Pro}^{55}, \mathrm{Gln}^{66}$, $\mathrm{Ser}^{67}, \mathrm{Glu}^{98}$ and $\mathrm{Asp}^{99}$ (alignment positions in GST of M. nipponense 7, 11, 46, 50, 59, 60, 61, 72, 73, 101 and 102, respectively) [33,34]. The second ligand binding site, H-sites, interacting with electrophilic xenobiotic substrates, contained eight conserved residues: $\mathrm{Tyr}^{7}, \mathrm{Phe}^{8}, \mathrm{Val}^{10}, \mathrm{Arg}^{13}, \mathrm{Val}^{104}, \mathrm{Tyr}^{108}, \mathrm{Asn}^{204}$ and $\mathrm{Gly}^{205}$ [35]. Most of these characteristic amino acids were found in GST of M. nipponense, with the exception of $\mathrm{Asn}^{53}, \mathrm{Asn}^{99}$ in the G-sites and $\mathrm{Try}^{8}, \mathrm{Ile}^{10}$ in the H-sites, which were respectively substituted for $\mathrm{Gln}^{53}, \mathrm{Asp}^{99}$ and $\mathrm{Phe}^{8}, \mathrm{Val}^{10}$. The predominant cat and gst expression in the hepatopancreas agreed with previous studies on white shrimp, Litopenaeus vannamei [36] and tilapias [37]. Therefore, the hepatopancreas was selected to detect cat and gst gene expression following exposure to MC-LR as the main antioxidative tissue of $M$. nipponense.

The rate or amounts of reactive oxygen species (ROS) generation can be induced by the presence of a wide range of natural and anthropogenic xenobiotics or toxins [38]. Much evidence suggested that MCs-induced oxidative damage could be a result of ROS generation $[39,40]$. The SOD-CAT system provides the first defense against oxygen toxicity. SOD catalyzes the dismutation of the superoxide radical to molecular oxygen and hydrogen peroxide [41]. Increased SOD activity is part of the adaptive mechanism to oxidative stress [42]. In the present study, the SOD activity was all stimulated by MC-LR 
at $0.2-25 \mu \mathrm{g} / \mathrm{L}$ in the early stage of exposure (12-72 h), and with an exposure duration from $12-48 \mathrm{~h}$, the increase of SOD activity was shown to be time-dependent at almost four concentrations. The results indicated that the antioxidant defense system of $M$. nipponense was rapidly activated after being exposed to MC-LR and had high efficiency to restore oxidative balance. In 96-h exposure, MC-LR tended to inhibit SOD activity, especially at $25 \mu \mathrm{g} / \mathrm{L}$, which was in line with the results in a previous study on freshwater mussel Dreissena polymorpha [43]. It is suggested that the exposure duration or concentration for MC-LR is not sufficient to provoke an increase in activity of the species. Pigeolet et al. [44] demonstrated that SOD was itself susceptible to oxidation and was suppressed by peroxides and oxygen derived free radicals. Therefore, in the present study, the high level of ROS at the end of exposure (96-h) might be detrimental to SOD activity. CAT is a key enzyme to remove the $\mathrm{H}_{2} \mathrm{O}_{2}$ produced by SOD catalyzing dismutation of highly reactive superoxide anions [45]. In the present study, the CAT activity was increased by MC-LR in the early stage of exposure (12-48 h), which indicated an activation of antioxidant defense system and non-lagged direct or indirect ROS production upon MC-LR exposure. However, at the end of exposure (96-h), the CAT activity had decreased with significant suppression at 1 and $25 \mu \mathrm{g} / \mathrm{L}$. In estuarine crab Chasmagnathus granulates, seven-day MC exposure also caused a decrease of CAT activity [46]. Previous study suggested that peroxides and oxygen derived free radicals inhibited CAT activity [44,47]. So, we speculate that the CAT might be suppressed by extra ROS at the end of exposure.

GSTs are a group of multifunctional dimeric proteins involved in cellular detoxification reaction, catalyzing the enzymatic conjugation of GSH to toxic compounds, including MCs [48]. The reaction will neutralize the electrophilic sites of MCs, increasing their water solubility and favoring their excretion [49]. In mussel Dreissena polymorpha, crustacean Daphnia magna and zebrafish Danio rerio, MC-LR glutathione conjugates were formed enzymatically via soluble GST [50], which suggested that GSTs played a key role in detoxification of MC-LR. GSTs contain two forms: the soluble form (sGST) and the membrane form (mGST). The sGST is found in the cell cytosol and mGST is bound to membrane of microsome, peroxisome, mitochondria and endoplasmic reticulum. In the present study, the sGST and mGST were not separated, so the GST activity signifies a combination of sGST and mGST activities. In the freshwater shrimp Palaemonetes argentines exposed to MCs, activity of sGST and mGST had a similar regulatory trend at any exposure time point [51]. So, we speculate that modulation of sGST in hepatopancreas of M. nipponense upon MC-LR may have a similar trend to the regulation of total GST activity in the present study. In the present study, mu-GST activity was significantly stimulated by MC-LR at $0.2-25 \mu \mathrm{g} / \mathrm{L}$ from $48-96 \mathrm{~h}$, which was consistent with the results of studies on other aquatic organisms such as crab and fish [52,53].

The function of GPx is to reduce free hydrogen peroxide to water and to reduce lipid hydroperoxides to their corresponding alcohols. GPx activity in the M. nipponense hepatopancreas was not significantly affected during the early stage of MC-LR exposure (12-24 h), while it was significantly stimulated by MC-LR even at $0.2 \mu \mathrm{g} / \mathrm{L}$ in the later stage of exposure $(72-96 \mathrm{~h})$. It seems that the enzymatic activity stimulation for GPx and CAT in response to MC-LR complements each other in the early and later stage of exposure. It suggested that the activation of GPx by MC-LR exposure might lag behind CAT.

Although increasing numbers of researches have focused on the oxidative stress responses arising from MCs, most of them were limited and mainly examined the changes in antioxidative enzymatic activity. Recently, differential expression of the genes encoding these antioxidant proteins has been used 
to detect biological toxicity $[54,55]$. In the present study, the transcriptional changes for $g s t, \mathrm{Cu} / \mathrm{Zn}-s o d$, cat, and gpx genes generally followed a similar trend to the changes in the respective enzyme activities in M. nipponense exposed to MC-LR. gst, $\mathrm{Cu} / \mathrm{Zn}$-sod, cat, and gpx transcription generally changed with higher amplitude compared with the activities of their respective enzymes during MC-LR exposure, suggesting that changes in transcription of antioxidant enzymes could serve as sensitive molecular biomarkers for exposure to MC-LR in M. nipponense, particularly for gst genes. In several exposure scenarios, the enzyme transcriptional changes were inconsistent with the changes in enzyme activities, such as CAT after the 12- and 24-h MC-LR exposures at $25 \mu \mathrm{g} / \mathrm{L}$ and GST and GPx after the 12- and 24-h MC-LR exposures at 5 and $25 \mu \mathrm{g} / \mathrm{L}$. This discrepancy suggested that the mRNA level of an enzyme signified a snapshot of its activity at any given time point, whereas enzyme activity may be regulated post-transcriptionally [56]. A study on common carp, Cyprinus carpio, exposed to MC showed that a time window probably exists between transcription and translation, as enzyme activity and mRNA expression were detected simultaneously [57].

\section{Conclusions}

In the present study, the full lengths of gst and cat cDNAs were firstly isolated in M. nipponense, and their putative amino acid sequences displayed high similarity to their respective counterparts of crustacean species. The mRNAs of gst and cat were mainly expressed in the hepatopancreas. The activity and transcriptional level variations of biotransformation enzyme (GST) and antioxidant enzymes (SOD, CAT, and GPx) indicated that MC-LR induced ROS production and crayfish made corresponding reaction to restore oxidative balance. The transcriptional response was generally more immediate and with greater amplitude than the enzyme activity responses, particularly for GST, which suggested that transcription of these genes could be a sensitive molecular biomarker for acute MC-LR exposure.

\section{Supplementary Materials}

Supplementary materials can be accessed at: http://www.mdpi.com/2072-6651/7/10/4006/s1.

\section{Acknowledgments}

The work was support by the Science Development Foundation of Zhejiang Province, China (No. 2012C12907-2).

\section{Author Contributions}

Zaizhao Wang and Zhiming Gu conceived and designed the study. Julin Yuan and Xueqin Wang performed the experiments. Julin Yuan wrote the paper. Zaizhao Wang and Yingying Zhang reviewed and edited the manuscript. All authors read and approved the manuscript.

\section{Conflicts of Interest}

The authors declare no conflict of interest. 


\section{References}

1. Pearson, L.; Mihali, T.; Moffitt, M.; Kellmann, R.; Neilan, B. On the chemistry toxicology and genetics of the cyanobacterial toxins, microcystin, nodularin saxitoxin and cylindrospermopsin. Mar. Drugs 2010, 8, 1650-1680.

2. Bieczynski, F.; Anna, J.D.; Pirez, M.; Brena, B.M.; Villanueva, S.S.M.; Luquet, C.M. Cellular transport of microcystin-LR in rainbow trout (Oncorhynchus mykiss) across the intestinal wall: Possible involvement of multidrug resistance-associated proteins. Aquat. Toxicol. 2014, 154, 97-106.

3. Honkanen, R.E.; Codispoti, B.A.; Tse, K.; Boynton, A.L. Characterization of natural toxins with inhibitory activity against serine/threonine protein phosphatases. Toxicon 1994, 32, 339-350.

4. Wang, X.T.; Chen, Y.; Zuo, X.T.; Ding, N.Q.; Zeng, H.J.; Zou, X.; Han, X.D. Microcystin (-LR) induced cell apoptosis via up-regulating apoptosis-related genes in vivo. Food Chem. Toxicol. 2013, 60, 309-317.

5. Van der Merwe, D.; Sebbag, L.; Nietfeld, J.C.; Aubel, M.T.; Foss, A.; Carney, E. Investigation of a Microcystis aeruginosa cyanobacterial freshwater harmful algal bloom associated with acute microcystin toxicosis in a dog. J. Vet. Diagn. Investig. 2012, 24, 679-687.

6. Kamjunke, N.; Mendonca, R.; Hardewig, I.; Mehner, T. Assimilation of different cyanobacteria as food and the consequences for internal energy stores of juvenile roach. J. Fish Biol. 2002, 60, 731-738.

7. Fischer, W.J.; Dietrich, P.J. Pathological and biochemical characterization of microcystin-induced hepatopancreas and kidney damage in carp (Cyprinus carpio). Toxicol. Appl. Pharm. 2000, 164, 73-81.

8. Best, J.H.; Eddy, F.B.; Codd, G.A. Effect of purified microcystin-LR and cell extracts of Microcystis strains PCC7813 and CYA43 on cardiac function in brown trout (Salmo trutta) alevins. Fish Physiol. Biochem. 2001, 24, 171-178.

9. Qiu, T.; Xie, P.; Guo, L.; Zhang, D. Plasma biochemical response of the planktivorous filter-feeding silver carp (Hypophthalmichthys molitrix) and bighead carp (Aristichthys nobilis) to prolonged toxic cyanobacterial blooms in natural water. Environ. Toxicol. Pharmacol. 2009, 27, 350-356.

10. Cazenave, J.; Wunderlin, D.A.; Bistoni, M.; Amé, M.V.; Krause, E.P.; Flugmacher, S. Uptake, tissue, distribution and accumulation of microcystin-RR in Corydoras paleatus, Jenynsia multidentata and Odontesthes bonariensis: A field and laboratory study. Aquat. Toxicol. 2005, 75, 178-190.

11. Pires, L.M.D.; Kusserow, R.; Van, D.E. Influence of toxic and non-toxic phytoplankton on feeding and survival of Dreissena polymorpha (Pallas) larvae. Hydrobiologia 2003, 491, 193-200.

12. Juhel, G.; Davenport, J.; Ohalloran, J.; Culloty, S.; Ramsay, R.; James, K. Pseudodiarrhoea in zebra mussels Dreissena polymorpha (Pallas) exposed to microcystins. J. Exp. Biol. 2006, 209, 810-816.

13. DeMott, W.; Dhawale, S. Inhibition of protein phosphatase activity in three zooplankton species by microcystin-LR, a toxin from cyanobacteria. Arch. Hydrobiol. 1995, 34, 417-424.

14. Winston, G.W.; Giulio, R.T. Prooxidant and antioxidant mechanisms in aquatic organisms. Aquat. Toxicol. 1991, 19, 137-161.

15. Cadenas, E. Biochemistry of oxygen toxicity. Annu. Rev. Biochem. 1989, 58, 79-110. 
16. Prieto, A.I.; Pichardo, S.; Jos, Á.; Moreno, I.; Cameán, A.M. Time-dependent oxidative stress responses after acute exposure to toxic cyanobacterial cells containing microcystins in tilapia fish (Oreochromis niloticus) under laboratory condition. Aquat. Toxicol. 2007, 84, 337-345.

17. Sun, H.; Lü, K.; Minterc, E.J.A.; Chen, Y.; Yang, Z.; Montagnes, D.J.S. Combined effects of ammonia and microcystin on survival, growth, antioxidant responses, and lipid peroxidation of bighead carp Hypophthalmythys nobilis larvae. J. Hazard. Mater. 2012, 221-222, 213-219.

18. Atencio, L.; Moreno, I.; Jos, A.; Pichardo, S.; Moyano, R.; Blanco, A.; Cameán, A.M. Dose-dependent antioxidant responses and pathological changes in tenca (Tinca tinca) after acute oral exposure to Microcystis under laboratory condition. Toxicon 2008, 52, 1-12.

19. Li, W.; Chen, J.; Xie, P.; He, J.; Guo, X.C.; Tuo, X.; Zhang, W.; Wu, L.Y. Rapid conversion and reversible conjugation of glutathione detoxification of microcystins in bighead carp (Aridtichthys nobilis). Aquat. Toxicol. 2014, 147, 18-25.

20. Pflugmacher, S.; Wiegand, C.; Oberemm, A.; Beattie, K.A.; Krause, E.; Codd, G.A. Identification of an enzymatically formed glutathione conjugate of the cyanobacterial hepatoxin microcystin-LR: The first step of detoxication. Biochim. Biophys. Acta 1998, 1425, 527-533.

21. Wang, H.; Wang, J.; Wu, T.; Qin, F.; Hu, X.; Wang, L.; Wang, Z. Molecular characterization of estrogen receptor genes in Gobiocypris rarus and their expression upon endocrine disrupting chemicals exposure in juveniles. Aquat. Toxicol. 2011, 101, 276-287.

22. Thompson, J.D.; Gibson, T.J.; Plewniak, F.; Jeanmougin, F.; Higgins, D.G. The ClustalX windows interface: Flexible strategies for multiple sequence alignment aided by quality analysis tools. Nucleic Acids Res. 1997, 25, 4876-4882.

23. Saitou, N.; Nei, M. The neighbor-joining method-a new method for reconstructing phylogenetic trees. Mol. Biol. Evol. 1987, 4, 406-425.

24. Tamura, K.; Dudley, J.; Nei, M.; Kumar, S. MEGA4: Molecular Evolutionary Genetics Analysis (MEGA) software version 4.0. Mol. Biol. Evol. 2007, 24, 1596-1599.

25. Rasmussen, R. Quantification on the Light Cycler. In Rapid Cycle Real-Time PCR, Methods and Applications; Meuer, S., Wittwer, C., Nakagawara, K., Eds.; Springer Press: Heidelberg, Germany, 2001; pp. 21-34.

26. Sun, S.; Ge, X.; Fu, H.; Zhu, J.; Zhang, S.; Qiao, H. Molecular cloning and expression analysis of the hemocyanin gene from oriental river prawn (Macrobrachium nipponense). J. Fish. Sci. China 2014, 21, 229-238.

27. Livak, K.J.; Schmittgen, T.D. Analysis of relative gene expression data using real-time quantitative

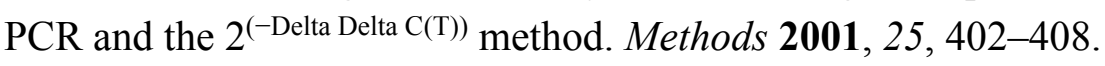

28. Chen, P.; Li, J.; Liu, P.; Gao, B.; Wang, Q.; Li, J. cDNA cloning, characterization and expression analysis of catalase in swimming crab Portunus trituberculatus. Mol. Biol. Rep. 2012, 39, 9979-9987.

29. Zhang, Q.; Li, F.; Zhang, X.; Dong, B.; Zhang, J.; Xie, Y.; Xiang, J. cDNA cloning, characterization and expression analysis of the antioxidant enzyme gene, catalase of Chinese shrimp Fenneropenaeus chinensis. Fish Shellfish Immunol. 2008, 24, 584-591.

30. Tavares-Sánchez, O.L.; Gómez-Anduro, G.A.; Felipe-Orteg, X.; Islas-Osuna, M.A.; Sotelo-Mundo, R.R.; Barillas-Mury, C.; Yepiz-Plascencia, G. Catalase from the white shrimp Penaeus (Litopenaeus) vannamei: Molecular cloning and protein detection. Comp. Biochem. Physiol. B 2004, 138, 331-337. 
31. Arockiaraj, J.; Easwvaran, S.; Vanaraja, P.; Singh, A.; Othman, R.Y.; Bhassu, S. Molecular cloning, characterization and gene expression of an antioxidant enzyme catalase (MrCat) from Macrobrachium rosenbergii. Fish Shellfish Immunol. 2012, 32, 670-682.

32. Yang, X.; Li, G.; Wen, C.; Hu, B.; Deng, L.; Pei, P.; Xie, Y. A catalase from the freshwater mussel Cristaria plicata with cloning, identification and protein characterization. Fish Shellfish Immunol. 2011, 31, 389-399.

33. Hu, B.; Deng, L.; Wen, C.; Yang, X.; Pei, P.; Xie, Y.; Luo, S. Cloning, identification and functional characterization of a pi-class glutathione-S-transferase from the freshwater mussel Cristaria plicata. Fish Shellfish Immunol. 2012, 32, 51-60.

34. Glisic, B.; Mihaljevic, I.; Popovic, M.; Zaja, R.; Loncar, J.; Fent, K.; Kovacevic, R.; Smital, T. Characterization of glutathione- $S$-transferases in zebrafish (Danio rerio). Aquat. Toxicol. 2015, $158,52-60$.

35. Won, E.J.; Kim, R.O.; Rhee, J.S.; Park, G.S.; Lee, J.; Shin, K.H.; Lee, Y.M.; Lee, J.S. Response of glutathione $S$-transferase (GST) gene to cadmium exposure in the marine pollution indicator worm, Perinereis nuntia. Comp. Biochem. Physiol. C 2011, 154, 82-92.

36. Carmen, A.; Contreras, V.; Citlalli, H.V.; Rogerio, R.; Sotelo, M.; Gloria, Y.P. A mu-class glutathione $S$-transferase from the marine shrimp Litopenaeus vannamei: Molecular cloning and active-site structure modeling. J. Biochem. Mol. Toxicol. 2004, 218, 245-252.

37. Yu, Y.; Liang, X.-F.; Li, L.; He, S.; Wen, Z.-Y.; Shen, D. Two homologs of rho-class and polymorphism in alpha-class glutathione $S$-transferase genes in the liver of three tilapias. Ecotoxicol. Environ. Saf. 2014, 101, 213-219.

38. Livingstone, D.R. Contaminant-stimulated reactive oxygen species production and oxidative damage in aquatic organisms. Mar. Pollut. Bull. 2001, 42, 656-666.

39. Li, X.; Liu, Y.; Song, L.; Liu, L. Response of antioxidant systems in the hepatocytes of common carp (Cyprinus carpio L.) to the toxicity of mcrocystin-LR. Toxicon 2003, 42, 85-89.

40. Amado, L.L.; Monserrat, J.M. Oxidative stress generation by microcystins in aquatic animals: Why and how. Environ. Int. 2010, 36, 226-235.

41. Pandey, S.; Parvez, S.; Sayeed, I.; Haque, R.; Bin-Hanfeez, B.; Raisuddin, S. Biomarker of oxidative stress: A comparative study of river Yamuna fish Wallago attu (B1. \& Schn.). Sci. Total Environ. 2003, 309, 105-115.

42. Velma, V.; Tchounwou, P.B. Hexavalent chromium-induced multiple biomarker responses in liver and kidney of goldfish, Carassius auratus. Environ. Toxicol. 2011, 26, 649-656.

43. Burmester, V.; Nimptsch, J.; Wiegand, C. Adaptation of freshwater mussels to cyanobacterial toxins: Response of the biotransformation and antioxidant enzymes. Ecotoxicol. Environ. Saf. 2012, 78, 296-309.

44. Pigeolet, E.; Corbisier, P.; Houbion, A.; Lambert, D.; Michiels, C.; Raes, M.; Zachary, M.D.; Remacle, J. Glutathione peroxidase, superoxide dismutase, and catalase inactivation by peroxides and oxygen derived free radicals. Mech. Ageing Dev. 1990, 51, 283-297.

45. Chance, B.; Sies, H.; Boveris, A. Hydroperoxide metabolism in mammalian organs. Physiol. Rev. 1979, 59, 527-605. 
46. Pinho, G.L.L.; da Rosa, C.M.; Maciel, F.E.; Bianchini, A.; Yunes, J.S.; Proenca, L.A.O.; Monserrat, J.M. Antioxidant responses and oxidative stress after microcystin exposure in the hepatopancreas of an eatuarine crab species. Ecotoxicol. Environ. Saf. 2005, 61, 353-360.

47. Escobar, J.A.; Rubio, M.A.; Lissi, E.A. SOD and catalase inactivation by singlet oxygen and peroxyl radicals. Free Radic. Biol. Med. 1996, 20, 285-290.

48. Takenaka, S. Covalent glutathione to cyanobacterial hepatotoxin microcystin LR by F344 rat cytosolic and microsomal glutathione $S$-transferases. Environ. Toxicol. Pharm. 2001, 9, 135-139.

49. Ito, E.; Takai, A.; Kondo, F.; Masui, H.; Imanishi, S.; Harada, K. Comparison of protein phosphatase inhibitory activity and apparent toxicity of microcystins and related compounds. Toxicon 2002, 40, $1017-1025$.

50. Hou, J.; Li, L.; Xue, T.; Long, M.; Su, Y.J.; Wu, N. Hepatic positive and negative antioxidant responses in zebrafish after intraperitoneal administration of toxic microcystin-LR. Chemosphere 2015, 120, 729-736.

51. Galanti, L.N.; Amé, M.V.; Wunderlin, D.A. Accumulation and detoxification dynamics of cyanotoxins in the freshwater shrimp Palaemonetes argentinus. Harmful Algae 2013, 27, 89-97.

52. Sabatni, S.E.; Brena, B.M.; Pirez, M.; Molina, M.C.R.; Luquet, C.M. Oxidative effects and toxin bioaccumulation after dietary microcystin intoxication in the hepayopancreas of the crab Neohelice (Chasmagnathus) granulata. Ecotoxicol. Environ. Saf. 2015, 120, 136-141.

53. Bieczynski, F.; Bianchi, V.A.; Luquet, C.M. Accumulation and biochemical effects of microcystin-LR on the Patagonianpe jerrey (Odontesthes hatcheri) fed with the toxic cyanobacteria Microcystis aeruginosa. Fish Physiol. Biochem. 2013, 39, 1309-1321.

54. Ríos, V.; Guzmán-Guilén, R.; Moreno, I.M.; Prieto, A.I.; Puerto, M.; Jos, A.; Cameán, A.M. Influence of two depuration periods on the activity and transcription of antioxidant enzymes in tilapia exposed to repeated doses of cylindrospermopsin under laboratory conditions. Toxins 2014, 6, 1062-1079.

55. He, S.; Liang, X.; Sun, J.; Shen, D. Induction of liver GST transcriptions by tert-butylhydroquinone reduced microcystin-LR accumulation in Nile tilapia (Oreochromis niloticus). Ecotoxicol. Environ. Saf. 2013, 90, 128-135.

56. Li, G.; Xie, P.; Fu, J.; Hao, L.; Xiong, Q.; Li, H. Microcystin-induced variations in transcription of GSTs in an omnivorous freshwater fish, goldfish. Aquat. Toxicol. 2008, 88, 75-80.

57. Amado, L.L.; Garcia, M.L.; Pereira, T.C.B.; Yunes, J.S.; Bogo, M.R.; Monserrat, J.M. Chemoprotection of lipoic acid against microcystin-induced toxicosis in common carp (Cyprinus carpio, Cyprinidae). Comp. Biochem. Physiol. C 2011, 154, 146-153.

(C) 2015 by the authors; licensee MDPI, Basel, Switzerland. This article is an open access article distributed under the terms and conditions of the Creative Commons Attribution license (http://creativecommons.org/licenses/by/4.0/). 